\title{
STATISTICAL MODELS FOR HEAT TREATING RENE'220C
}

\author{
R.G. Carison \\ EVGINEERING AND MATERIALS TECHNOLOGY IABORATORIES \\ GENERAL ELECTRIC AIRCRAFT ENGINES \\ CINCINNATI, 0HIO 45215
}

\begin{abstract}
Statistically designed studies on Rene'220C have indentified hardness and impact behavior with varying heat treatments. The Central Composite Design approach, used in this effort, is a powerful tool for developing heat treating models and thereby optimize parameters. Conclusions from this evaluation are that fine-grain ( $F G$ ) and conventionally cast (CC) Rene'220C not only exhibit different microstructures, but have different hardness and impact responses to the imposed heat treatments. Further, Rene'220C behaves as an "in situ" composite. The model shows an interaction between the two aging steps (AGE1 and AGE2) and hardness and reveals a "robust" design point. The impact response strongly depends on the first step (AGE1) of the two-step age cycle. A significant observation is that $C C$ material exhibits over 2 times the impact of FG material.
\end{abstract}




\section{INTRODUCTION AND BACKGROUND}

An ever increasing demand for more efficient aircraft engines provides a drive for improved cast $\mathrm{Ni}$-based superalloys. Rene'220C is a strong candidate for engine structural applications. Earlier, Rene'220C had been developed as a wrought alloy, then called $\mathrm{CH} 22^{2}$, but now is being successfully applied as a cast material on F110-129 turbine frames. Rene'220C's composition is similar to cast 718 , but contains controlled amounts of stengthening alloy elements. Although the composition approximates Cast 718 , the Fe has been replaced with $C o$, and $T a$ has been added.

Metallographic observations on Rene'220C have revealed similarities with cast 718. In both cases the composite .... and I emphaşise the composite ...nature of this structure has been clearly identified ${ }^{3}{ }^{4}$. This material distinguishes itself by the precipitation of the delta $(\delta)$ phase. Recent work compares small grained castings with conventional cast and HIP materials ${ }^{5}$. Such high $\mathrm{Cb}$ alloys have large liquidus-to-solidus gaps (ca. $350^{\circ} \mathrm{F}$ ) that aid metal flow and mold fill, but display extreme cast inhomogeneity with large dendrites .

The specific goal of this work is to investigate the interaction of hardness and impact properties for both conventionally cast and fine grain Rene'220C.

A powerful tool in developing and refining heat treat processes is statistics. Factorial experiments are most commonly used. Another scheme for evaluation of a process is by the Central Composite Design. An advantage of this approach is that it allows you to look at extended regions, or what are called "star" points, for enriched data analysis and modeling. In this effort, impact (as it relates to crack resistance) and hardness (as it depends on strength) are evaluated. Previous work evaluated the HIP temperatures, the delta precipitation temperature, and the initial step in the age cycle. Here the focus is on the delta precipitation temperature and the two age cycles.

\section{MATERIAL AND PREPARATION}

Two types of material were evaluated in this study. One was conventionally cast (CC) $R^{\prime} 220 C$, from a PCC cast turbine rear frame flange (\#015), as part of lot AL V0737. The second material type was fine-grain (FG), sometimes referred to as "Micro-Grain", cast $R^{\prime} 220 \mathrm{C}$, from Howmet lot VKK0002. Thesc two matcrials had similar chemistries. The conventionally cast flange was given the $2125^{\circ} \mathrm{F} / 4$ hours HIP cycle, while the fine-grained received a $2050^{8} \mathrm{~F} / 4$ hours HIP cycle. Both materials were solution treated at the $2000^{\circ} \mathrm{F} / 1$ hour condition. These materials were then heat treated in a statistically designed manner, shown in Table I and II.

\section{$\underline{A P P R O A C H}$}

\section{CENTRAL COMPOSITE DESIGN HEAT TREATMENT}

All specimens were vacuum heat treated to evaluate three post-solution treatments. First, the DELT treatment, precipitates the delta ( $\delta$ ) phase around the interdendritic regions, in a temperature range between $1615^{\circ} \mathrm{F}$ to $1785^{\circ} \mathrm{F}$ centered about $1700^{\circ} \mathrm{F}$, all for 4 hours. Second and third, the age cycles precipitates both gamma prime $\left(\gamma^{\prime}\right)$ and gamma double prime ( $\left.\gamma^{\prime \prime}\right)$. The initial age cycle, designated AGE1, specimens were heated between $1355^{\circ} \mathrm{F}$ and $1445^{\circ} \mathrm{F}$ centered about $1400^{\circ} \mathrm{F}$, all for, a time of 4 hours. The second part of the age cycle, designated AGE2, specimens were heated between $1280^{\circ} \mathrm{F}$ and $1370^{\circ} \mathrm{F}$ centered about $1325^{\circ} \mathrm{F}$, all for a time of 8 hours. Again the summary of the three-block, 18 specimen, test matrix is shown in Table II. All sections were machined into Charpy specimen, hardness tested, impacted, and metallographically evaluated. 
Table I Hardness, Impact, \& Percent Delta Results For Fine Grain (FG)

Rene'220C.

\begin{tabular}{|c|c|c|c|c|c|c|c|c|c|c|}
\hline \multirow[b]{2}{*}{ Row } & \multicolumn{2}{|c|}{$\begin{array}{l}\text { Cursor at Row: } \\
\text { column: }\end{array}$} & \multicolumn{2}{|c|}{$\begin{array}{l}\text { Data Editor } \\
\text { File: RGC22030 }\end{array}$} & \multicolumn{2}{|r|}{ Row: } & \multicolumn{2}{|c|}{$\begin{array}{l}\text { Data Editor } \\
\text { File: RGC22030 }\end{array}$} & \multicolumn{2}{|r|}{$\begin{array}{l}\text { Maximum Rows: } 18 \\
\text { Number of Cols: } 12\end{array}$} \\
\hline & STA_NO & HIP_T & DEL_T & AGE1_T & AGE2 $2 T$ & T HAPD_DELAC & HARD_AGIRC & HARD_AG2RC & Impact & FLb per_DELTA \\
\hline $\begin{array}{c}1 \\
2 \\
3 \\
4 \\
5 \\
6 \\
7 \\
8 \\
99 \\
10 \\
11 \\
12 \\
13 \\
14 \\
15 \\
16 \\
17 \\
18 \\
19 \\
20\end{array}$ & $\begin{array}{l}1 . \\
2 . \\
3 . \\
4 . \\
5 . \\
6 . \\
7 . \\
8 . \\
9 . \\
10 . \\
11 . \\
12 . \\
13 . \\
14 . \\
15 . \\
16 . \\
17 . \\
18 . \\
19 .\end{array}$ & $\begin{array}{l}2050 . \\
2050 . \\
2050 . \\
2050 . \\
2050 . \\
2050 . \\
2050 . \\
2050 . \\
2050 . \\
2050 . \\
2050 . \\
2050 . \\
2050 . \\
2050 . \\
2050 . \\
2050 . \\
2050 . \\
2050 . \\
2050\end{array}$ & $\begin{array}{l}1650 . \\
1650 . \\
1750 . \\
1750 . \\
1700 . \\
1700 . \\
1650 . \\
1650 . \\
1750 . \\
1750 . \\
1700 . \\
1700 . \\
1785 . \\
1615 . \\
1700 . \\
1700 . \\
1700 . \\
1700 . \\
1700 / 8\end{array}$ & $\begin{array}{l}1375 . \\
1425 . \\
1375 . \\
1425 . \\
1400 . \\
1400 . \\
1375 . \\
1425 . \\
1375 . \\
1425 . \\
1400 . \\
1400 . \\
1400 . \\
1400 . \\
1445 . \\
1355 . \\
1400 . \\
1400 . \\
1425 .\end{array}$ & $\begin{array}{l}1300 . \\
1350 . \\
1350 . \\
13300 . \\
1325 . \\
1325 . \\
3350 . \\
1300 . \\
1300 . \\
3350 . \\
1325 . \\
1325 . \\
1325 . \\
1325 . \\
1325 . \\
1325 . \\
1370 . \\
1280 . \\
1300 .\end{array}$ & $\begin{array}{l}24.2 \\
24.0 \\
20.5 \\
21.2 \\
23.4 \\
22.4 \\
22.1 \\
23.5 \\
22.7 \\
21.2 \\
23.5 \\
22.6 \\
18.5 \\
24.8 \\
22.0 \\
22.4 \\
24.6 \\
22.4 \\
22.8\end{array}$ & $\begin{array}{l}35.2 \\
38.3 \\
35.3 \\
38.1 \\
36.2 \\
36.7 \\
35.7 \\
37.0 \\
36.5 \\
38.3 \\
38.0 \\
37.0 \\
37.8 \\
37.7 \\
36.5 \\
35.0 \\
38.3 \\
38.9 \\
38.3\end{array}$ & $\begin{array}{l}39.6 \\
40.6 \\
40.4 \\
42.2 \\
11.4 \\
41.1 \\
39.9 \\
22.6 \\
20.5 \\
41.6 \\
41.5 \\
11.6 \\
40.5 \\
39.5 \\
42.3 \\
39.5 \\
41.2 \\
41.3 \\
11.5\end{array}$ & $\begin{array}{l}7.59 \\
6.51 \\
7.23 \\
6.15 \\
6.44 \\
6.73 \\
7.23 \\
6.36 \\
8.10 \\
6.58 \\
6.51 \\
6.36 \\
7.16 \\
6.58 \\
5.71 \\
7.96 \\
7.09 \\
6.58 \\
6.58\end{array}$ & $\begin{array}{l}15 . \\
15 . \\
25 . \\
25 . \\
20 . \\
25 . \\
10 . \\
15 . \\
30 . \\
25 . \\
15 . \\
20 . \\
30 . \\
5 . \\
15 . \\
20 . \\
15 . \\
10 . \\
25\end{array}$ \\
\hline Typ & $\begin{array}{l}18 \\
\text { w/ } 8 \\
288 \text { th } \\
2 E d i t\end{array}$ & $\begin{aligned} 18 \\
\text { H/ } \\
\text { key } \\
\text { savscr } \\
\text { ins: } \\
105\end{aligned}$ & $\begin{array}{r}18 \\
\text { N/ } \\
\text { e updo } \\
\text { tscr } 5 \\
\text { TGRAPH }\end{array}$ & $\begin{array}{l}18 \\
N / 7 \\
\text { ata or } \\
660 \\
\text { ers. } 2.6\end{array}$ & & 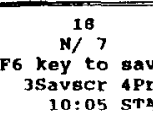 & $\begin{array}{c}18 \\
18 \\
\text { Ne } \\
\text { ve updated } \\
\text { rtscr sopts } \\
\text { ATGRAPHICs }\end{array}$ & $\begin{array}{l}18 \\
N / 7 \\
\text { date or the } \\
660 \\
\text { vers. } 2.6\end{array}$ & 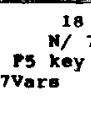 & $\begin{array}{l}{ }_{7}^{18} \\
1 / 8 \\
\text { for other } \\
\text { BCmd } 9 \text { options. } \\
\text { Display }\end{array}$ \\
\hline
\end{tabular}

Table II Hardness, Impact, \& Percent Delta Results For Conventionally Cast (CC) Rene'220C.

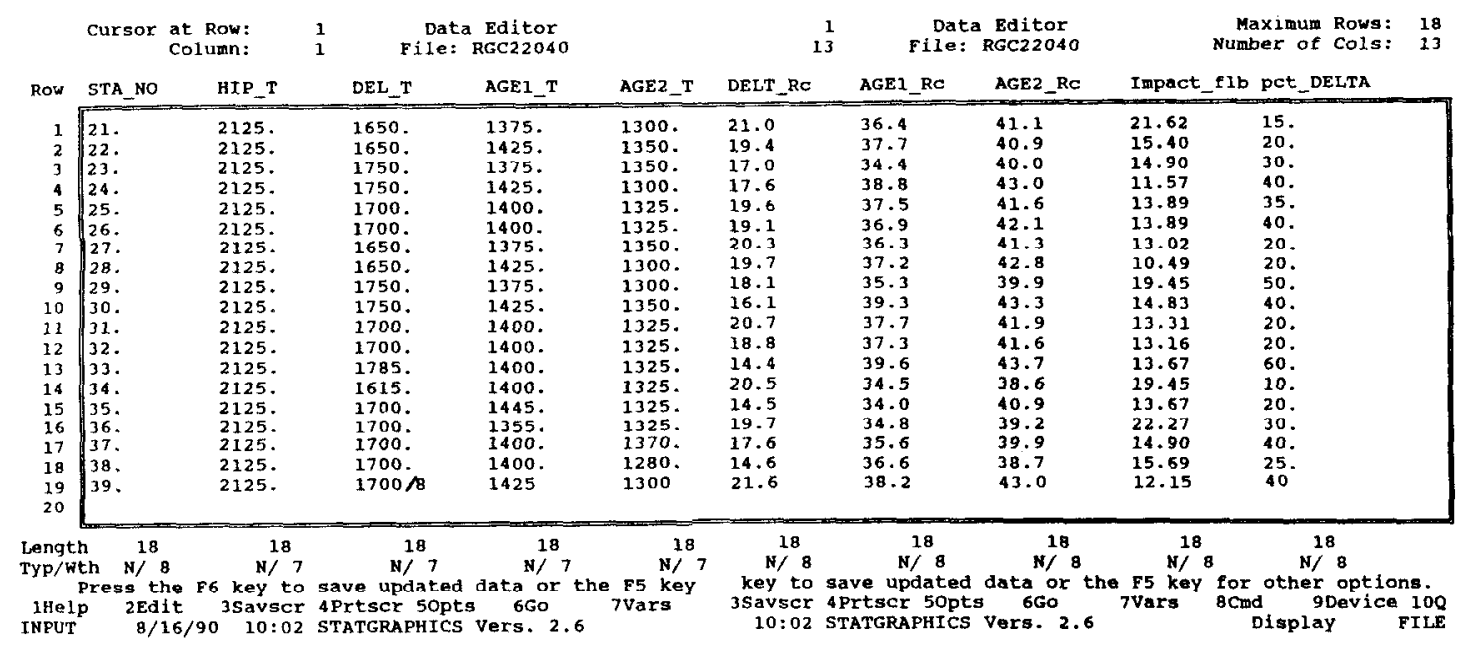




\section{TESTING}

Charpy specimens were machined with the length along the periphery of the flange and along the plate length, and the machined impact surface on the flange's and plate's outer surfaces.

Evaluations of the dependent variables of hardness, charpy impact, and metallographic structure were made. AlI measurements were performed on the Charpy specimens. Rockwell $C$ hardness tests, a minimum of three per specimen, were made in identical locations on each specimen away from the impact area. Charpy testings were performed on an Amsler-Schnadt impact machine. One-half of each fractured Charpy bar was mounted for optical metallography, polished and etched electrolytically at $2-3$ volts in Rife's etchant $\left(62.5 \% \mathrm{H}_{2} \mathrm{O}, 22.5 \%\right.$ $\mathrm{HCl}, 7.5 \% \mathrm{HNO}_{3}, 7.5 \% \mathrm{HF}$, and $5 \mathrm{gms} \mathrm{CuCl}_{2}$ ). Scanning electron microscopy (SEM) was performed in the Cambridge instrument and dispersive $x$-ray analysis (EDAX) was made at $20 \mathrm{KV}$. The grain size and volume percent of delta $(\delta)$ were both determined by a lineal analysis technique.

\section{RESULTS}

All hardness and impact data are recorded in Table I for the fine-grain material and in Table II for the conventionally cast material.

\section{HARDNESS}

There are three types of hardness data. The first was taken after the delta treatment (DELT); the second after the initial age treatment (AGE1), and the third was after the second part of the double-age cycle (AGE2). The data after the AGE2 cycle was considered to represent the full heat treatment, and most of the statistical evaluation was made on these data.

After the DELT heat treat cycle, the hardness levels for both the FG and CC materials are about $5 \mathrm{RC}$ points higher than the starting hardness of the as-solutioned material, i.e., 18.5 (FG) vs. 13.5 (CC). The lower temperature reaction probably forms a finer $\delta$ phase in the grain boundries, and thereby $\delta$ age-hardens the material by about $5 \mathrm{Rc}$ points above the as-solutioned material. Following the AGE1, the first part of the dual age, there appears to be a maxima at slightly over $1400^{\circ} \mathrm{F}$. This results from the precipitation of fine, coherent $\gamma^{\prime \prime}$ particles. Both materials now exhibit the same hardness level, ca. 37 Rc.

After the AGE2. the second part of the dual age, the materials are considered to be representative of the full heat treatment, and in general indicate a hardness peak at about $1325^{\circ} \mathrm{F}$. Although the CC material is slightly harder, the FG material displays less scatter. These hardness values result from both the $\gamma^{\prime}$ and $\gamma^{\prime \prime}$ precipitations. The contour plots for both $F G$ and CC under these conditions are shown in Figures 1, 2, 3, and 4. Interesting to note is that the maximum hardness for the FG material is more influenced by the DELT temperatures, while the CC material is controlled more by the AGE2 temperature (Figure 1 and 2). Further, the CC matcrial reveals a distinct hardness maxima for the AGE1 and AGE2 temperatures at $1440^{\circ} \mathrm{F}$ and $1315^{\circ} \mathrm{F}$ (Figure 4), which also is shown in Figure $4 \mathrm{~A}$ as a doom-shaped area on the surface plot. 


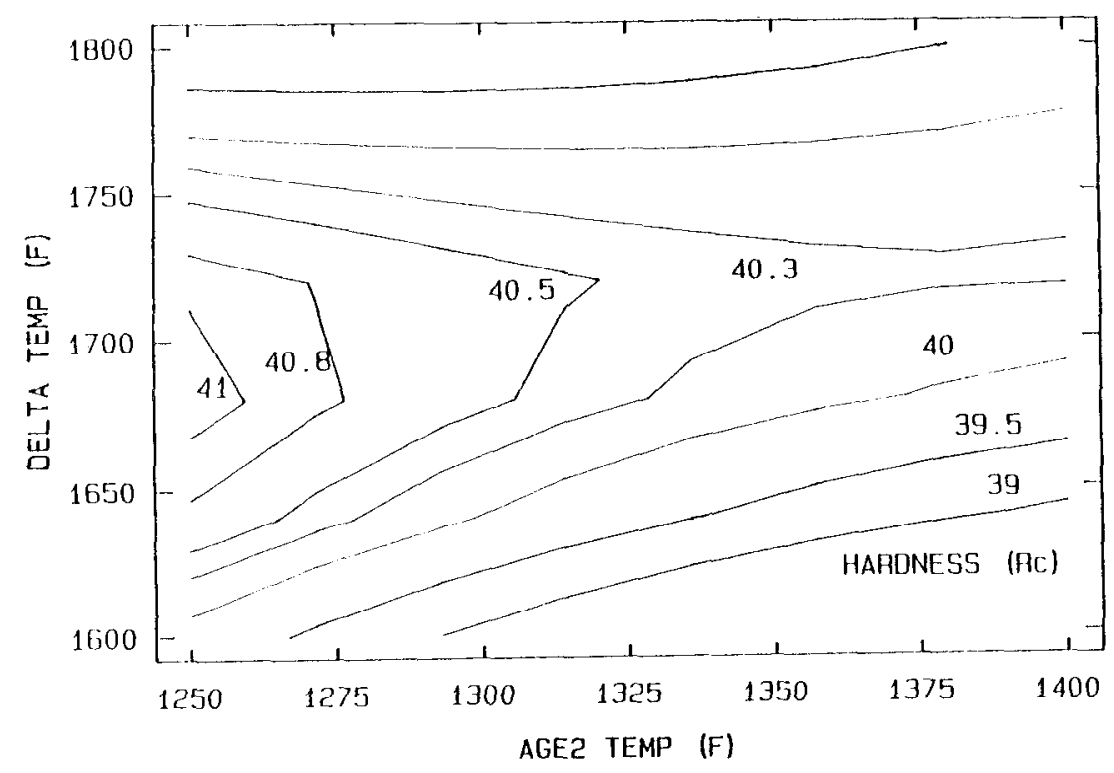

F1gure 1. Hardness(Full HT) Vs. DELT \& AGE2 Temperatures (Fine Grain Rene'220G).

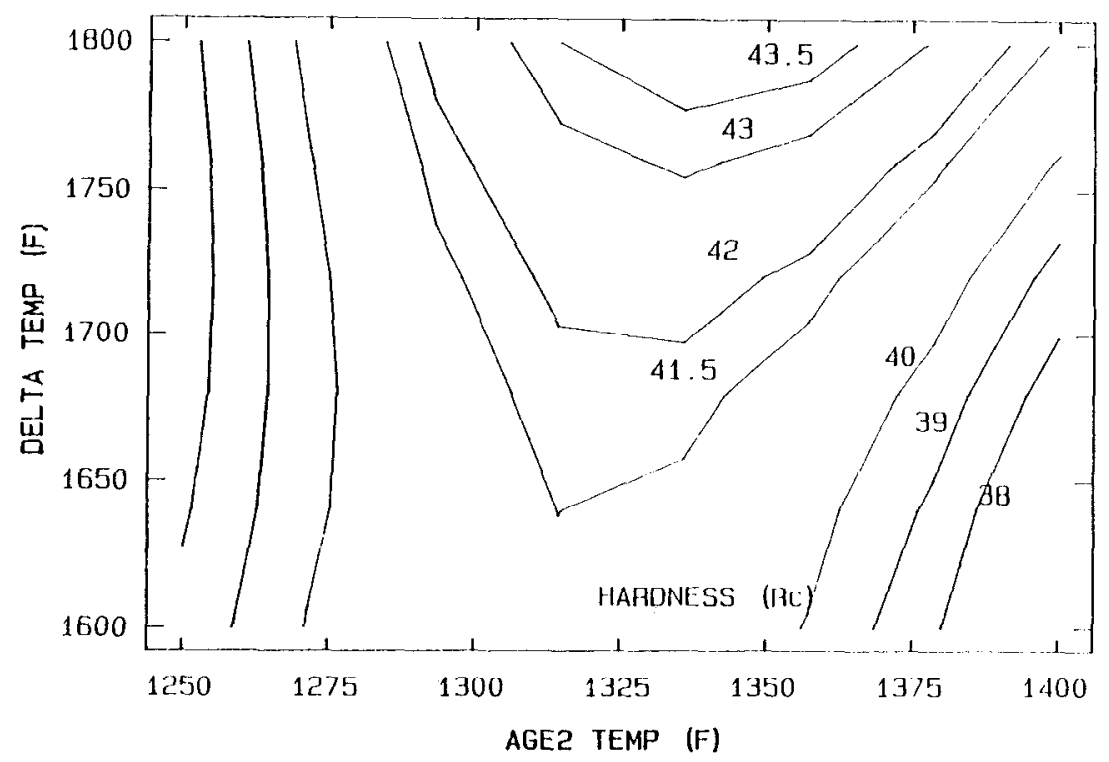

Figure 2. Hardness(Ful1 HT) Vs. DELT \& AGE2 Temperatures (Conventionally Cast Rene'220C). 


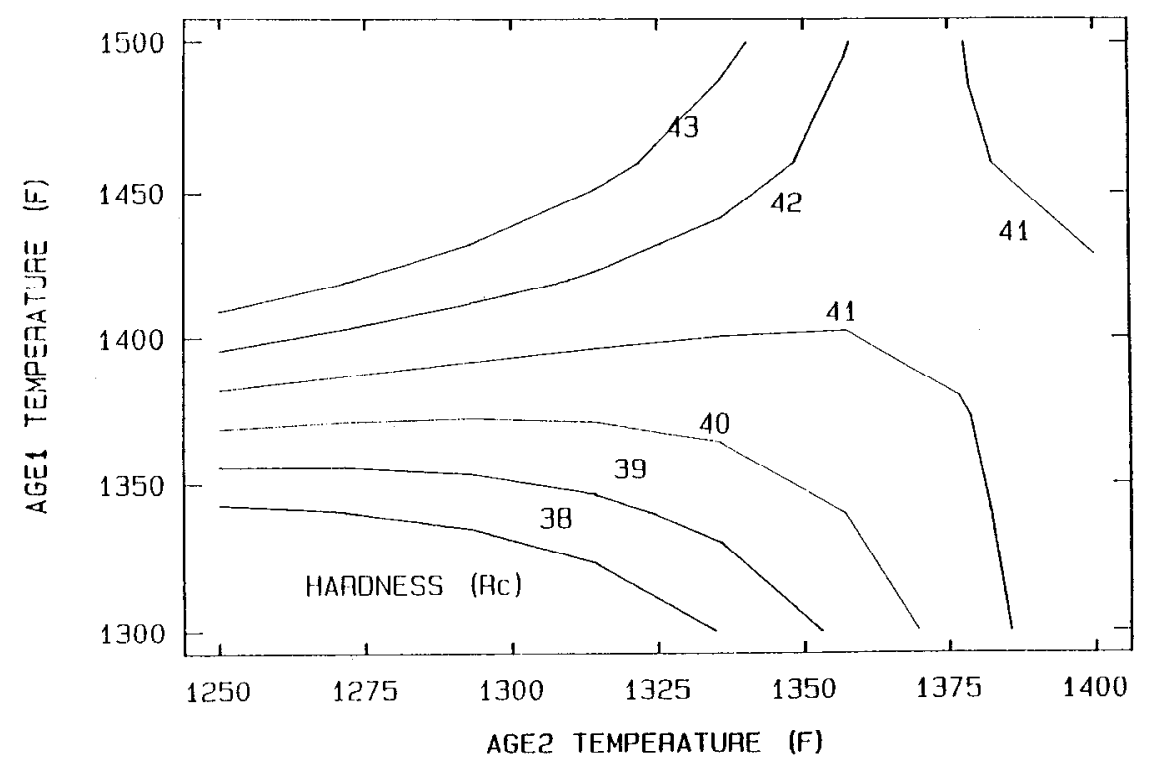

Figure 3. Hardness(Full HT) Vs. AGE1 \& AGE2 Temperatures (Fine Grain Rene'220C).

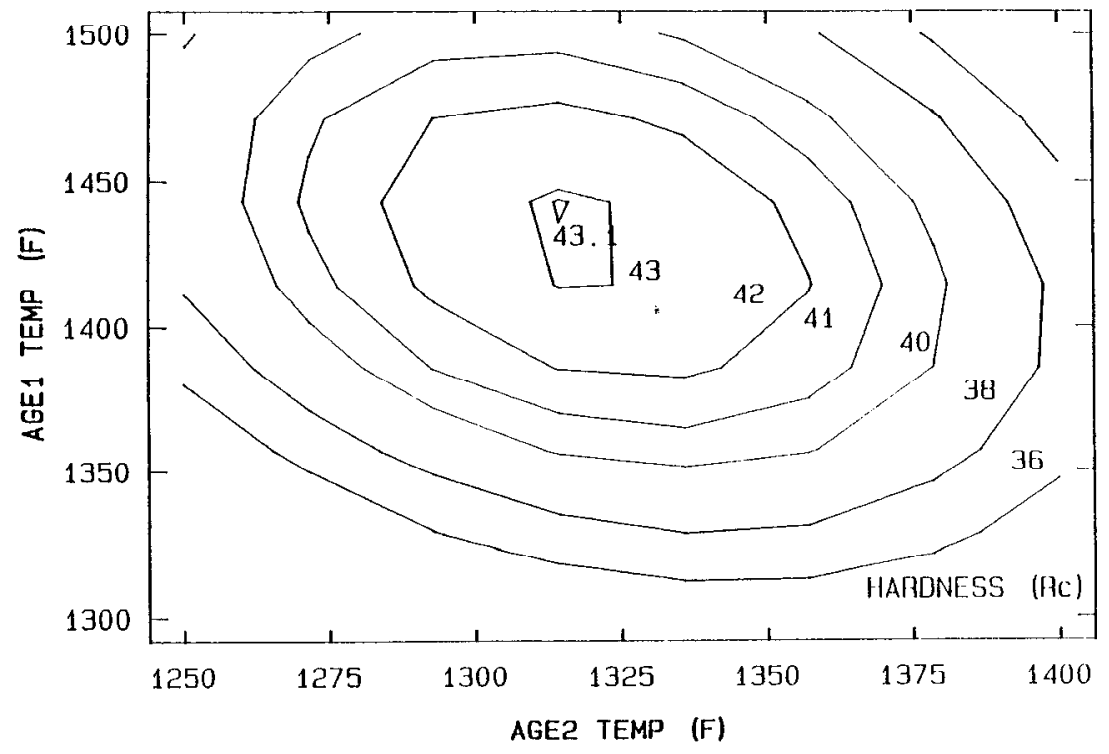

Figure 4. Hardness(Full HT) Vs. AGEl \& AGE2 Temperatures (Conventional1y Cast Rene'220C). 


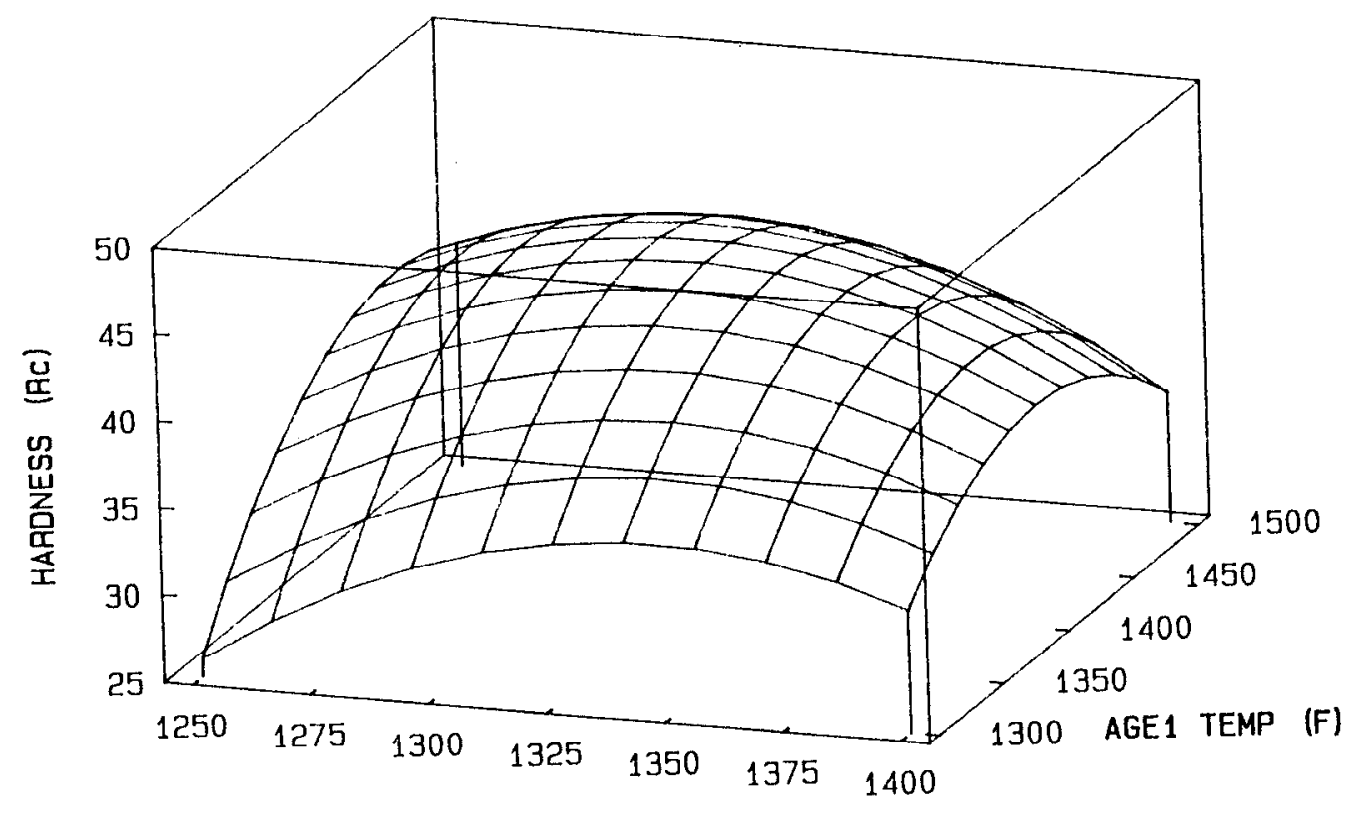

AGE2 TEMP (F)

\section{Figure 4A. Hardness(Full HT) Vs. AGE1 \& AGE2 Temperatures (Conventiona11y Cast Rene'220C).}

\section{IMPACT}

The Charpy impact results are recorded in Table I and II. These impact energy relationships with the independent processing variables are shown in contour plots, Figure 5, and 6. Clearly noted is that the impact strengths for Lhe $C C$ material are over twice that of the FG material. For both $F G$ and $C C$ materials, the AGEl temperature produces an inverse relationship (more pronounced for the CC material), with the lowest AGE1 temperature generating the highest impact values. This suggests that the $\gamma^{\prime \prime}$ controls impact to a greater extent, and probably the fine $\gamma^{\prime \prime}$ distribution enhances energy absorption. This $\gamma^{\prime \prime}$ feature is described later.

Comparing the FG material impact (Figure 5) with hardness (Figure 3) it can be noted that impact can be increased, with little hardness loss, by decreasing both AGE1 and AGE2 temperatures. Likewise, for the CC material, comparing Figure 6 (impact) with Figure 4 (hardness), that by decreasing the AGE1 temperature to $1400^{\circ} \mathrm{F}$ increasing the AGE2 temperature to $1325^{\circ} \mathrm{F}$, the hardness would increase (higher strength), and more importantly, impact could be significantly increased (almost 25\%). 


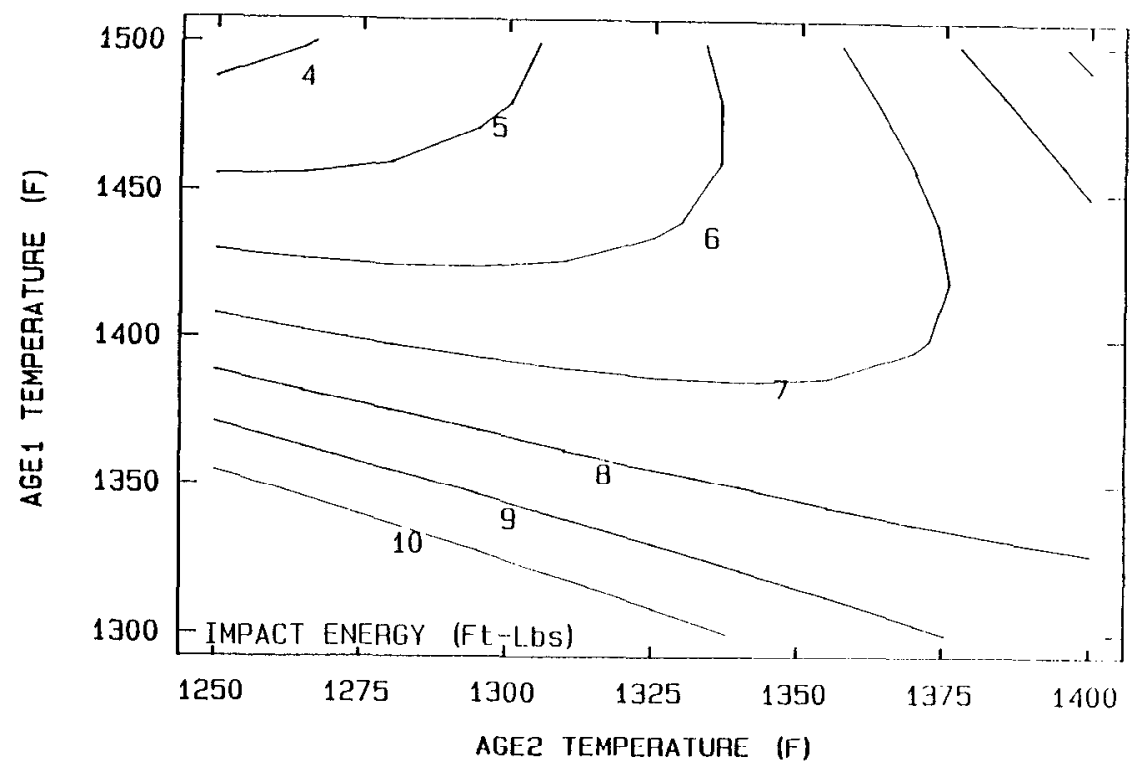

Figure 5. Impact Vs. AGE1 \& AGE2 Temperatures (Fine Grain Rene'220C).

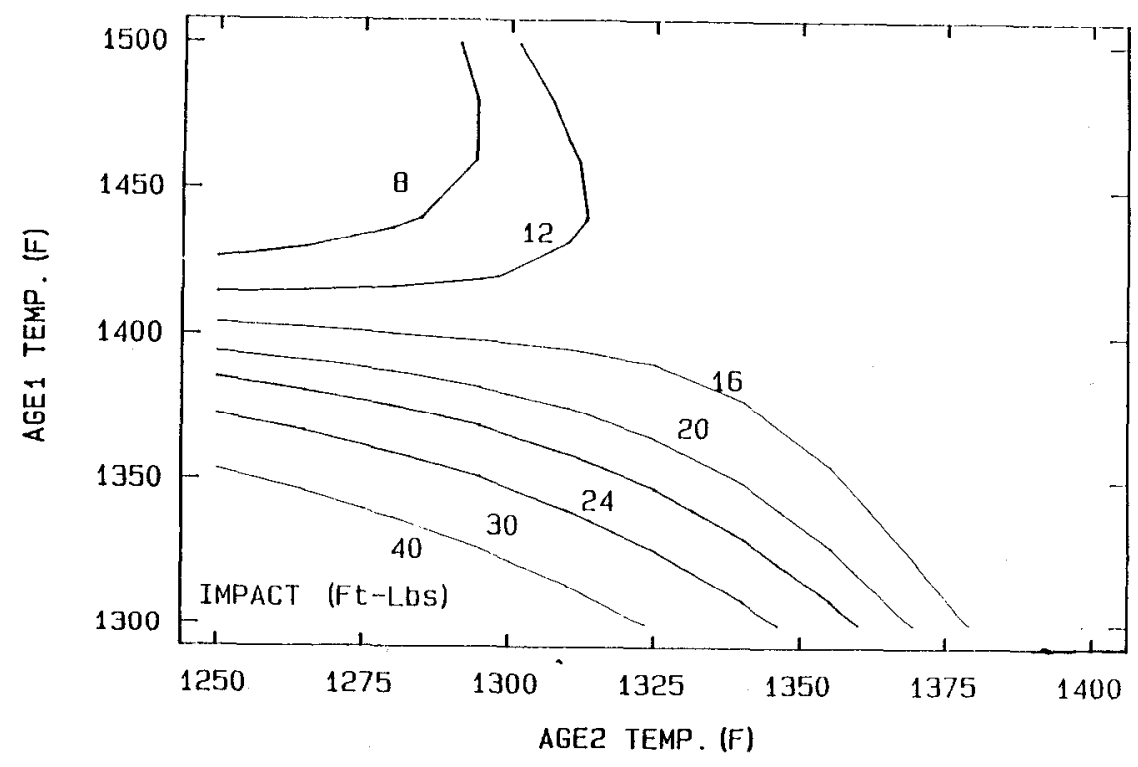

Figure 6. Impact Vs. AGEl \& AGE2 Temperatures (Conventionally Cast Rene'220C). 


\section{METALLOGRAPHY}

Metallographic cxaminations on the etched material show distinct differences between the $F G$ and $C C$ materials as seen in Figures 7 and 8 . The surfaces were first lightly etched to reveal the $\delta$ phase, then more heavily etched to enhance the grain boundry regions. In most cases the $\delta$ plates are etched away leaving behind the $\delta$ trenches.

The microstructures clearly show the FG's more equiaxed grain structure, and the CC's dendrite nature. These structures reveal the varying amounts of needle-1ike $\delta$ phase. The $\delta$ phase is a complexed $\mathrm{Ni}{ }_{3} \mathrm{Cb}(\mathrm{Ta})$ structure, usually orthorhombic, with a number of different features: $\delta$ can appear as globular eutectic, needle-like (most commonly noted form), "blocky", or fine. The $\delta$ needles appear to deform extensily, even at room temperature, but at higher magnification this deformation is seen as a "kinking" behavior.

The $1650^{\circ} F$ DELT treatment not only limits the needle $\delta$ formation, but also produces a "halo" effect. This "halo" effect is identificd with the the presence of a $\gamma^{\prime \prime}$ (or a fine $\delta$-1ike) precipitate in the region adjacent to the grain boundry. Also noted was that $\gamma^{\prime \prime}$ precipitation occurs in the previous traces of the solutioned $\delta$ needles. At first it may seem strange that $\gamma^{\prime \prime}$ forms in the vestiges of the previously dissolved $\delta$, but it is not too surprising, since both $C b$ and $T a$ have not diffused away, and $\delta$ and $\gamma^{\prime \prime}$ are essentially the same $\mathrm{Ni}_{3} \mathrm{Cb}(\mathrm{Ta})$ chemistries. This provides a "memory" for structure morphology.

Estimates of the amount of needle $\delta$ phase as a function of DELT werc made. The observed percent increases monotonously with increasing DELT temperature. Again, it needs to be pointed out that the observed percent of the needle $\delta$ phase was a lineal analysis of the area and does not account for the depleted area between the $\delta$ plates. Further, these amounts depict neither the quality nor the fineness of $\delta$ phase. Higher magnifications (5000X) reveal the $\delta$ to be coarser at higher DELT temperatures.

Highly significant is the composite nature of both cast alloy. The dendrite regions are lightly alloyed matrix sprinkled with $\gamma^{\prime}$ and $\gamma^{\prime \prime}$, while the interdendritic regions, in addition to $\gamma^{\prime}$ and $\gamma^{\prime \prime}$, have extensive build-ups of $C b$ and $T a$ and contain carbides and $\delta$. EDAX examination of the interdendritic region reveal the presence of a small amount of $C b(T a)$ carbide and the coarse ("blocky") eutectic $\delta$; the matrix emits a normal trace for the Rene'220C matrix.

Estimates of the ASTM grain size of both the FG and CC materials were made. The average grain size for the FG was 4.2 , while for the CC material it was about -4 .

There is a distinct difference in the crack propagation modes for FG and CC Rene'220C. The FG cracks follow, almost exclusively, the grain boundries, while for the CC material cracking migrates across dendrites. These dendrites appear to act as barriers and provide crack blunting. Hence, given the opportunity, cracks will propagate through the more brittle interdendric network. 

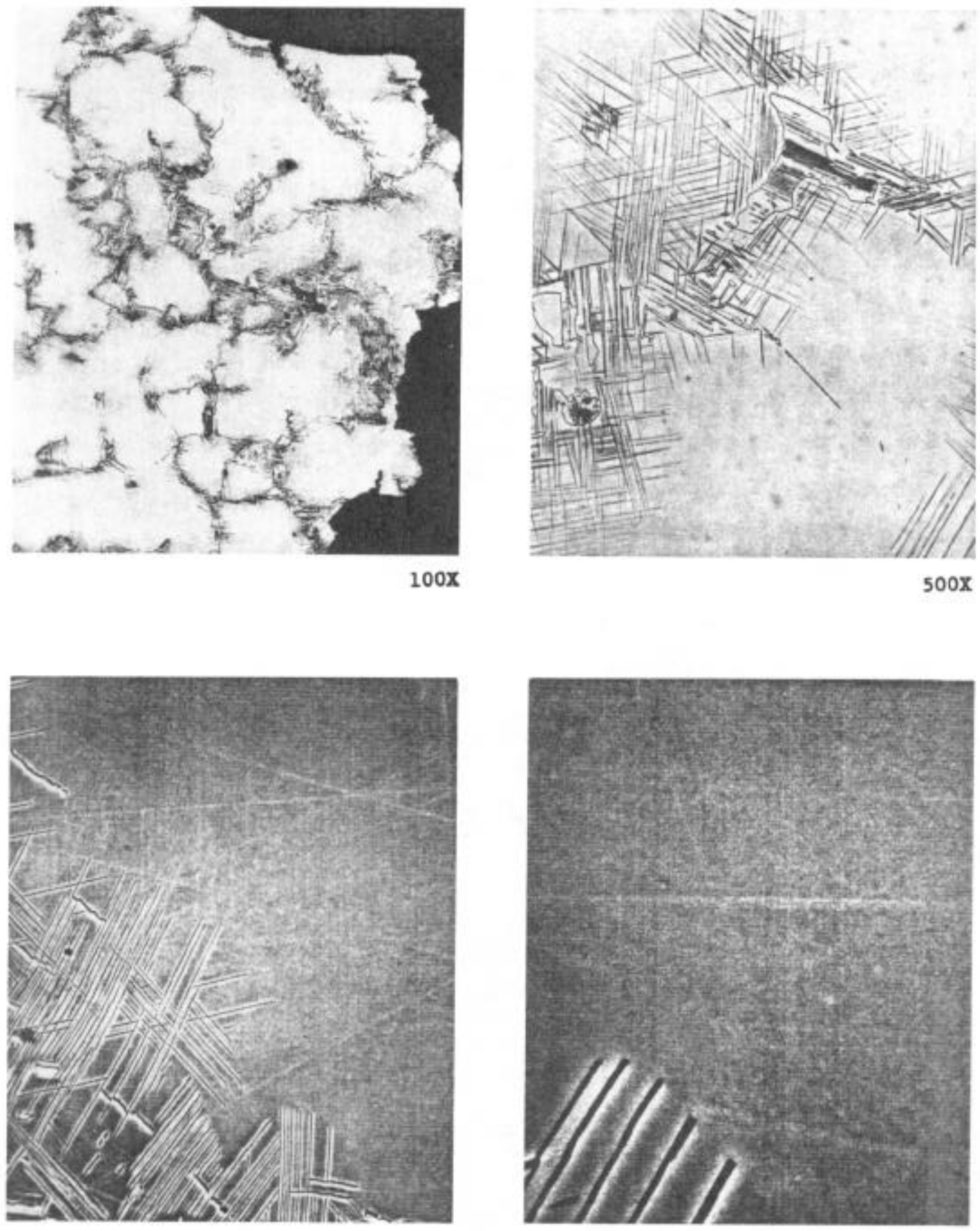

F1gure 7. Optical and SEM Microviews of Specimen 13, Fine Grain(FG) R'220C, After the $1785^{\circ} \mathrm{F} / 4 \mathrm{Hour}$ (DELT) $+1400^{\circ} \mathrm{F} / 4 \mathrm{Hour}$ (AGE1) + $1325^{\circ} \mathrm{F} / 8$ Hour (AGE2) Heat Treatment. 

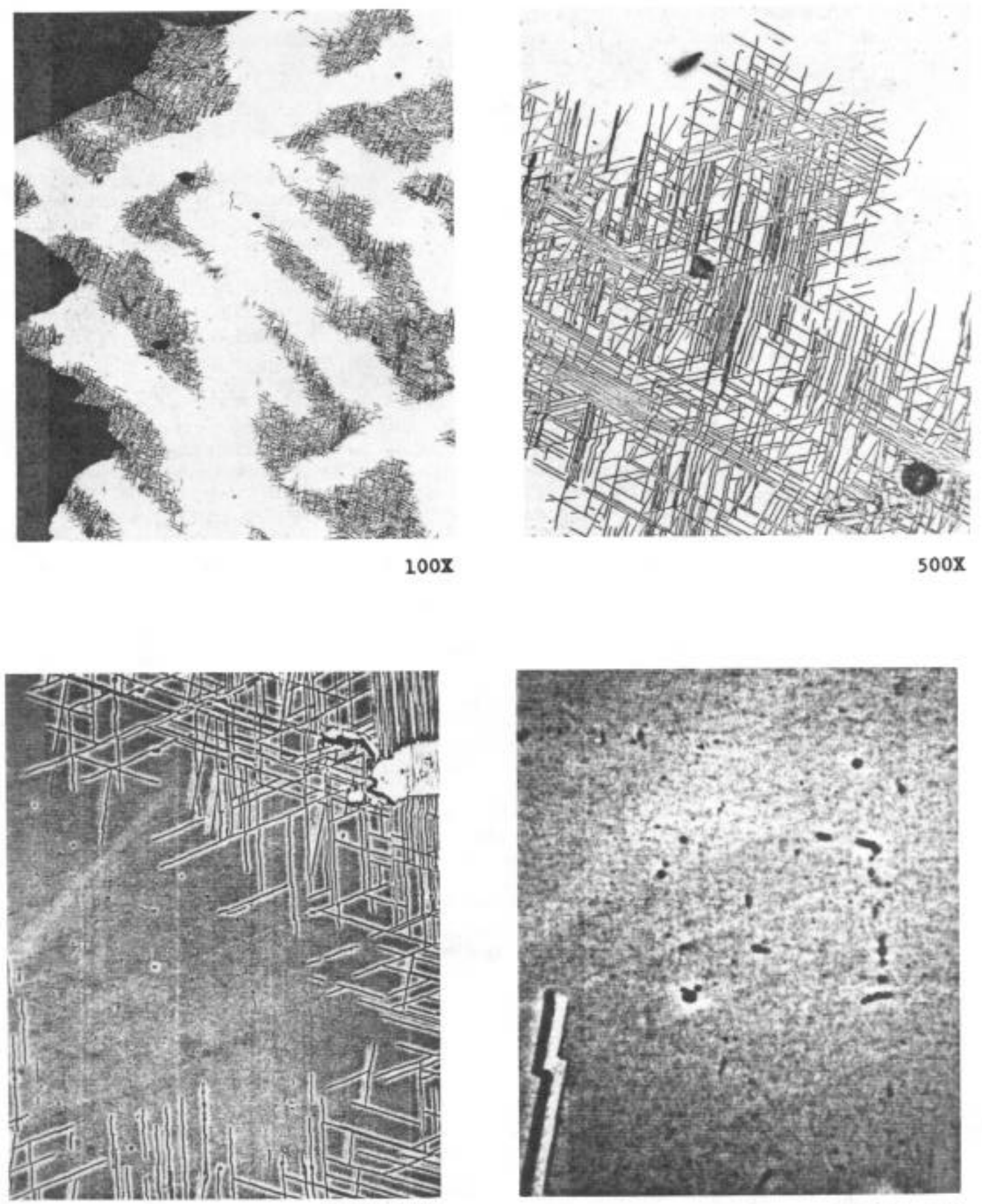

$1000 X$ SEM

$5000 X$ SEM

Figure 8, Optical and SEM Microviews of Specimen 33, Conventional1y Cast(CC) R'220C, After the $1785^{\circ} \mathrm{F} / 4 \mathrm{Hour}(\mathrm{DELT})+$ $1400^{\circ} / 4$ Hour (AGE1) $+1325^{\circ} \mathrm{F} / 8$ Hour (AGE2) Heat Treatment. 


\section{DISCUSSION}

Both fine grain ( $F G$ ) and conventionally casst (CC) Rene'220C materials are "in situ" composites, as previously noted", . Properties of these materials are dependent on this composite-like structure.

Hardness of both FF and CC materials are inversely proportional to impact absorption. These hardness levels increase as a funtion of the imposed independent processing variables, DELT, $A G E 1$, and $A G E 2$. The baseline values, after the $2000 F / 1$ hour solution, are $R C=18.5$ for the $F G$ and $R c=13.5$ for the $C C$.

The DELT treatment increases the hardness levels about 5 points, to $R c=22.5$ for the $F G$ and $R c=18.3$ for the $C C$. Further noted was that the lower DELT temperatures produce higher hardness; not surprising, since this hardness increase is due to the $\delta$ precipitation, with the lower temperatures producing the finer $\delta$ precipitation.

The AGEl treatment increases the hardness level over 15 points, to $R C=37.0$ for the $F G$ and $R c=36.7$ for the $C C$. In both cases a peak appears at about $1425^{\circ} \mathrm{F}$. Probability this hardness increase results from $\gamma^{\prime \prime}$ precipitation.

The AGE2 treatment produces an additional hardness increase of about 4 points, to $R C=41$ for the $F G$ and $R c=41.4$ for the $C C$. This added hardness increase accurs from the $\gamma^{\prime}$ precipitation. Undoubtably $\gamma^{\prime}$ precipitation occurs in close proximity with the $\gamma^{\prime \prime}$, in a "sandwich" $\gamma^{\prime} / \gamma^{\prime}$ structure, previously noted. No hardness peaks appear, but rather the AGE2/hardness curves are relatively flat between $1300^{\circ} \mathrm{F}-1350^{\circ} \mathrm{F}$.

Interactions are note between the AGE1 and AGE2 treatments, notably for the CC material, which reveals a hardness peak (at $A G E l=1440^{\circ} \mathrm{F}$ and $A G E 2=1315^{\circ} \mathrm{F}$ ). This peak probably results from the maximum matrix strain from the coprecipitation of $\gamma^{\prime \prime}$ and $\gamma^{\prime}$, and results in the highest strength levels. In a statistical design parlance, this maxima represents a "robust" design point, since it would offer the best parameter condition to minimize the dependent property loss with variation in the independent processing variables. However, this property point must also be balanced with the other property values considered, in this case, impact.

The CC Rene'220C exhibits more than two times the impact of FC Rene'220C. The reason for this relates to structure and the mode of crack propagation. CC material contains more dendrites and these aid in crack blunting

Impact property is found to be relatively insensitive to DELT and AGE2 treatment, i.e. the curves remain flat. However, impact is most sensitive to the AGEl treatment. For both the FG and CC material, the lower the AGEI temperature, the greater the impact. This is probably due to the formation of a finer $\gamma^{\prime \prime}$ within the interface between the dendrite and the interdendritic regions.

If one makes the assumption that interdendritic regions offer no resistance to crack growth (impact energy absorbtion), then all the energy is absorbed by the dendrites. The impact behavior is determined soley by the nature of the dendrites. Also let us assume that the impact energy has a direct relationship to the crack hold-time growth behavior. More than likely this assumption is not valid, that all the energy is absorbed by the dendrites, but rather some of the energy is absorbed by the interdendritic regions. gther studies have shown the $\delta$ distribution influences the crack growth behavior.

It should be recognized that the as-cast structure is transient. With each suceeding heat treatment, $C b$ and $T a$ tend to level-out. The fine needle-like $\delta$ provides more effective crack-blunting. When "sufficient" $\mathrm{Cb}$ and Ta diffuse (at temperatures above $1700^{\circ} \mathrm{F}$ for long times) then coarse $\delta$ can decorate the grain boundry and embrittle the material. 
In summaxy, a statistically designed heat treat study of Rene'220C indentified the hardness and impact interactions as a functions of DELT, AGE1, and AGE2 treatments.

The main conclusions from this study are:

1. The fine grain (FG) Rene'220C and conventionally cast (CC) Rene'220C differ not only microstructurally, but exhibit different hardness and impact properties.

2. The CC Rene'220C has over 2 times the impact of FG Rene'220C.

3. Impact is strongly dependent on the AGEl treatment (the first step in the double age cycle) with lower temperatures resulting in higher values.

4. The "in situ" composite nature of Rene'220C is reconfirmed.

5. The CC Rene'220C exhibits a rather unique interaction with the AGE 1 and AGE2 treatments; hardness can be chosen from a "robust" design point.

6. The heat treat models aid in understanding the heat treatment responses.

7. This Central Composite Design approach is a powerful method to determine heat treat interaction, and thereby optimize parameters for desired properties.

\section{ACKNOWLEDGEMENTS}

John Snyder, Eric Boerger, and Mike Connelly performed all HIP and vacuum heat treat cycles. Geoff Meadows was most helpful in metallography, while Judy Mescher did an outstanding job in SEM. Discussions with Bob Fields, Tom Kelly, Stan Wlodek and Barney Lawless aided my thinking on the morphology and precipitation mechanisms. Bill Ross supplied the conventionally cast (CC) Rene'220C flange for this evaluation. I also want to acknowledge the support from the F110, the GE90, and the Rocketdyne ALS programs.

\section{REFERENCES}

1. K.-M.Chang and A.H.Nahm, "Rene'220C: 100 F Improvement Over Alloy 718", Proceedings of symposium on Superalloy 718 - Metallurgy and Application, E.A.Loria, Editor, TMS, 1989.

2. R.H.Roth and J.W.Brantly, "A Challenge In Structural Design", The Leading Edge, GE Aircraft Engines, Summer 1989.

3. R.G.Carlson and J.F.Radavich, "Microstructural Characterization of Cast 718", Proceedings of symposium on Superalloy 718 - Metallurgy and Application, E.A.Loria, Editor, TMS, 1989.

4. S.T.Wlodck and R.D.Field, "Stability, Structural Reactions in Rene'220C Including Heat Treatment and Long Time Exposure Studies", R87AEB472, July 27, 1987.

5. G.K.Bouse and M.R.Behrendt, "Mechanical Properties of Microcast-X Alloy 718 Fine Grain Castings", Proceedings of Symposium on Superalloy 718-Metallurgy and Application, E.A.Loria, Editor, TMS, 1989

6. R.G.Car1son, "Micro-Grain Rene'220C Response To Heat Treatments" TM89-371, September 19, 1989 .

7. B.H.Lawless and J.F.Barker, "TMP of Rene'220W For Improved Crack Growth Resistance", R90AEB295, June 1990. 